\title{
Roles and mechanisms of stem cell in wound healing
}

\author{
Thurga Ayavoo $^{1}$, Karthikeyan Murugesan ${ }^{1,2}$, Ashok Gnanasekaran ${ }^{1,2}$ \\ ${ }^{1}$ Centre of Research for Infectious Diseases and Phytochemical Studies, Quest International University Perak, Perak, Malaysia; ${ }^{2}$ Department of \\ Microbiology, Faculty of Medicine, Quest International University Perak, Perak, Malaysia \\ Contributions: (I) Conception and design: All authors; (II) Administrative support: None; (III) Provision of study materials: All authors; (IV) Collection \\ and assembly of data: All authors; (V) Data analysis and interpretation: All authors; (VI) Manuscript writing: All authors; (VII) Final approval of \\ manuscript: All authors. \\ Correspondence to: Ashok Gnanasekaran. Centre of Research for Infectious Diseases and Phytochemical Studies, Quest International University Perak, \\ 30250 Ipoh, Perak, Malaysia. Email: gnanasekaran.ashok@qiup.edu.my.
}

\begin{abstract}
Wound healing phases comprise of highly synchronized process that begins due to a damage and restores the integrity of the injured tissues. Wound healing reduces the damage in tissue and supply sufficient oxygen and tissue perfusion, provide proper nourishment and humid wound healing atmosphere to re-establish the essential status of exaggerated parts. The untreated wound becomes susceptible for pus development, bacterial infection and complications like sepsis. Traditional and modern approaches are in practice to treat acute, open and chronic injuries, however, present wound care management has met with challenges and minimal positive effects. Stem cells have possible wound healing capability to overwhelm restrictions of the current wound care practices as it produces faster tissue regeneration in wound repair. Stem cells are unspecialized cells derived from adult body tissues and embryos that differentiate into any cell of an organism and capable of self-regeneration. The understanding on molecular mechanisms of stem cells has become the central and promising field in scientific study. This review focuses on the pre-existing traditional and modern treatments for wound healing, and types and roles of stem cells in wound care management. This review also focuses on the fundamental molecular characterization and factors influencing the molecular mechanisms of stem cells in wound healing.
\end{abstract}

Keywords: Wound healing; stem cell; diabetic; cytokines; angiogenesis

Received: 14 June 2020; Accepted: 27 January 2021; Published: 02 March 2021.

doi: $10.21037 /$ sci-2020-027

View this article at: http://dx.doi.org/10.21037/sci-2020-027

\section{Introduction}

Wounds are physical injuries that occur due to internal and external breakage of skin that results in an opening or rupture of the skin $(1,2)$. An instant and proper wound healing is necessary for the re-establishment of functional tissues and disordered structural maintenance following an injury (3). This complex phenomenon involves constant cell-cell and cell-matrix interactions that promote healing of wounds in three different overlapping phases that are inflammatory phase, proliferative phase and remodelling phase as represented in Figure 1 (4).

\section{Inflammatory phase}

Inflammatory response is the reaction of body towards injuries that are caused by toxins, microorganisms and other means of pathogens. These injured cells secrete histamine that triggers the blood vessels to release fluid into tissues. This phenomenon results in inflammation. Blood coagulation and homeostasis are two significant events that occur in inflammatory phase immediately 


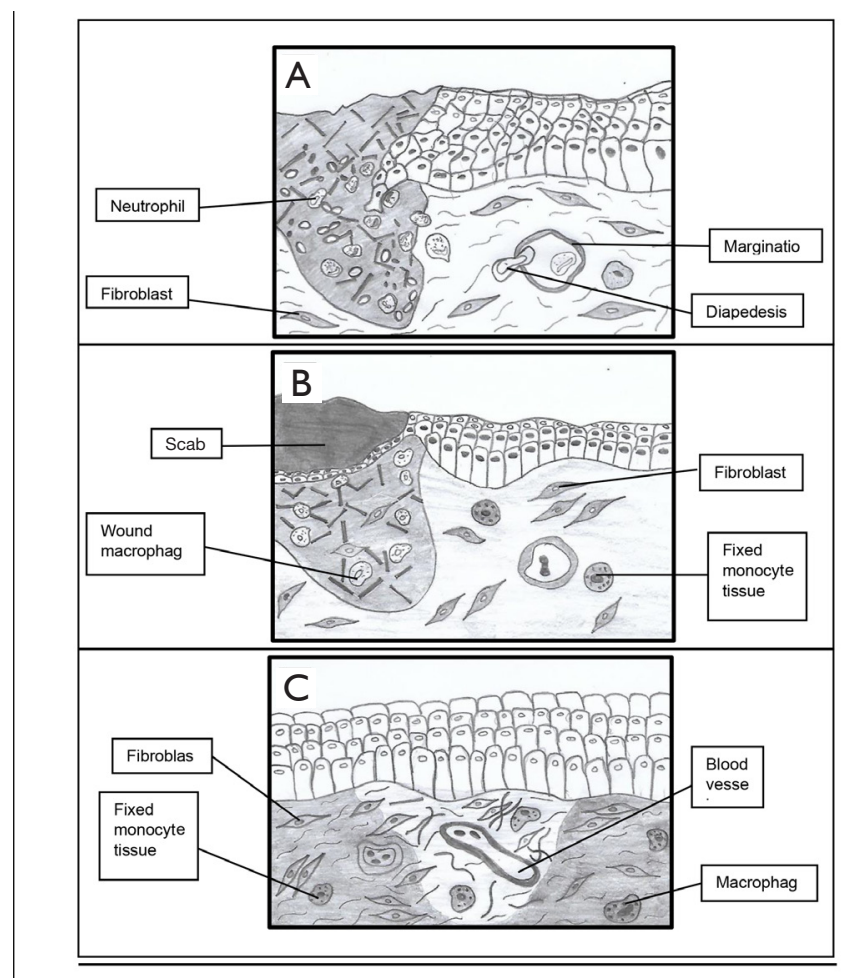

Figure 1 Phases of wound healing. (A) Inflammatory phase. The neutrophils attached to endothelial cells surrounding the wound bed initiate the inflammatory phase, a day after an injury. (B) Proliferation phase. Macrophages activated by fixed tissue monocytes kill the microorganisms and eliminate damaged extracellular matrix by releasing proteases. They release growth factors that stimulate fibroblasts to proliferate and fabricate scar tissue. (C) Remodelling phase. The disorganized scar tissue is gradually substituted by a matrix that merely be similar to the extracellular matrix of normal skin.

after injury to prevent extensive blood loss at site of injury wound and this phase persist for two days. The activation of blood coagulation results in aggregation of platelets and formation of clot. The process requires two important pathways, which are intrinsic and extrinsic pathways. The inflammation phase begins when homeostasis is attained (5).

\section{Proliferative phase}

In wound healing, proliferative phase begins on the third day of injury and persist for about two weeks. As this phase progress, transforming growth factor beta (TGF- $\beta$ ) released by macrophage, $\mathrm{T}$ lymphocytes and platelets become an important indicator to control the functions of fibroblast cells. Moreover, the fabrication of proteases that is essential for the breakdown of matrix is reduced by TGF- $\beta$. TGF- $\beta$ also has the capability to trigger the production of tissue inhibitor of metalloproteinase (TIMP) (4). The process of wound healing in proliferative phase involves angiogenesis, fibroblast migration and epithelialisation.

\section{Angiogenesis}

Angiogenesis is essential in normal processes such as corpus luteum formation, embryo development and wound healing (6). Following an injury, site of wound is comparatively avascular. It is fully dependent on distribution from healthy and normal capillaries at the damaged area. The activity of angiogenesis produces a rich vascular network of capillaries all over the lesion from branches of undamaged vessels (7). The confined factors such as reduced oxygen tension and lower $\mathrm{pH}$ that present surrounding the wound area are responsible for the induction of angiogenesis. Fibroblast cells, macrophages and epidermal cells fabricate basic fibroblast growth factor (bFGF), vascular endothelial cell growth factor (VEGF) and TGF- $\beta$ that stimulates angiogenesis (8). 


\section{Fibroblast migration}

Fibroblasts are predominant cells in proliferative phase as these cells responsible to produce new matrix required to re-establish the structure and shape of wounded tissue. The proliferations of fibroblast are triggered by TGF- $\beta$ and PDGF, discharged from haemostatic clot and then travel to the injury vessels (9). Fibroblast cells produce fibronectin and collagen by adhering to the fibrin matrix in the third day of wound. Following the release of collagen and fibronectin, granulation of tissue occurs at the wound area (7).

The healthy wound healing process involves the mass activity of fibroblast cells. The stimulation and proliferation of fibroblast cells are significant in the proliferative phase of wound healing (10). Collagen is an important factor that involves in wound healing. The reformation of granulation tissues are mediated by products of collagen breakdown that stimulates the cellular migration of cells (11). On the fifth day of wound, collagen matures and forms intermolecular and intramolecular cross-links between the capillaries that improve the efficiency of weak tissues (12).

\section{Epithelialisation}

The migration of epithelial cells from the wound area begin within a few hours of injury and the process prolongs until a single layer of cells are formed over the damaged area (13). As the mitotic activity of epithelial cells increases, the migrating cells form a complete layer over the wound and attach to cell matrix (7). This process completes when the matured epithelial cells assemble thus resulting in the formation of basement membrane (13).

\section{Remodelling phase}

Remodelling is the last phase in normal wound healing process that lasts for about one to two years, or even longer. The remodelling phase is characterized by balancing the synthesis and degradation of the extracellular matrix components (4). This progression marks the growth of regular epithelium and development of wound tissue (7). The development of granulation tissue indicates the initiation of regeneration of extracellular matrix in both proliferative and remodelling phases (13).

In remodelling phase, the contraction in surface of wound indicates fibroblasts differentiation into myofibroblasts (14). This stage involves equilibrium between production and deprivation, as the protein and collagen accumulated in the wound area become gradually better structured (7).
About $80 \%$ of the tissue strength can be recovered due to the activity of collagen fibres; however the final recovery of tissue depends on source of the repair and its period (13). As the wound healing process progresses, the quantity of macrophages and fibroblasts decreased, by a process called apoptosis. Following this phenomenon, development of capillaries stops, decrease in the blood flow to the wound site and decline in the metabolic activity is observed at the wound area, as the wound completely heals (12).

\section{Wound healing: pre-existing treatment}

Wound healing includes a well-organized biological and molecular sequences that involve cell migration, cell proliferation and deposition of extracellular matrix (15). This requires the assistance of traditional or modern approaches to further accelerate the wound healing process. Wound care experts use the conventional and alternative medicines to treat acute, normal and chronic wounds due to the development of multi-resistant microorganisms and a decline in novel antibiotics (16).

\section{Traditional approaches in wound healing}

World Health Organization (WHO) defines traditional medicine as the understanding on skills and applications based on the philosophies and knowledges native to diverse cultures, used in the health management and diagnosis, precaution or cure of mental and physical ailment (17). Traditional medicines are preferred by people due to their efficacy and milder side effects. Various range of traditional approaches such as plant extracts and herbal medicines are used in wound care management to treat the acute, normal and chronic wounds.

\section{Curcumin}

Curcumin is the indigenous polyphenol present in the rhizome of Curcuma longa and other Curcuma spp. (18). In Asian countries, Curcuma longa is used as a traditional herb in wound care and other physical illnesses due to its anti-inflammatory, anti-oxidant (19), anti-microbial (20) and anti-cancer properties (21). Curcumin modulates the inflammatory, proliferative and remodelling phases of wound healing (22).

Curcumin increases the production of anti-inflammatory cytokines vital for the inflammatory response by recruiting M2-like macrophages (23) to reduce the inflammation. Besides being an anti-inflammatory, curcumin possess 
antioxidant properties by scavenging the reactive oxygen species (ROS) produced by extrinsic factors (24). Curcumin increases the production of collagen and hydroxyproline in proliferative phase of wound healing (25). Curcumin has the capability to accelerate the process of wound healing by shortening the inflammatory phase (26).

\begin{abstract}
Aloe vera
Aloe barbadensis Miller is a cactus-like houseplant grows in hot environment (27). Aloe vera gel is used extensively in various natural treatments. The translucent mucilaginous gel is obtained from the parenchymal tissue of the leaf (28). The healing property of aloe vera can be used to treat skin damages, ulcers and acute burns. Aloe vera gel comprises therapeutic properties such as analgesic, anti-inflammatory and wound healing (29). The anti-inflammatory property of aloe vera improves the oxygenation at wound site, remove the free radicals, increases collagen and facilitates the vasoconstriction reduction (30).
\end{abstract}

\section{Modern approaches in wound bealing}

Modern medicine is an extensive set of healthcare applications that are not a part of traditional or alternative medicine (31). Moreover, modern medicine is not completely incorporated into the main healthcare management, where they are practised interchangeably with traditional medication. A vast range of modern approaches are being used by healthcare professionals for wound care management. However, excessive consumption of modern medicines may result in mild or severe side effects.

\section{Nonsteroidal anti-inflammatory drugs (NSAIDs)}

NSAIDs are some of the modern medicines available in the market for wound healing. Aspirin, naproxen and ibuprofen are examples of pain relievers that characterised as NSAIDs. NSAIDs depend on prostaglandins, a compound formed by a special enzyme that aids in reducing swelling and relieving pain and fever (32). NSAIDs reduce pain by suppressing the production of prostaglandin E2 (PGE-2), an inflammatory mediator (33). The NSAIDs drug has known antiproliferative effect on blood vessels and skin that delays the rate of wound healing (34).

\section{Liposome-encapsulated buflomedil hydrochloride}

Wound healing process involves neovascularization, the natural development of new blood vessels that are capable of perfusion by red blood cells. The progression of neovascularization can be accelerated through intake of modern drugs. Liposome-encapsulated buflomedil hydrochloride is a drug applied topically to quicken the neovascularization in wound healing. The use of liposomeencapsulated buflomedil hydrochloride is significant in wound healing as it accelerates wound closure rate compared to unloaded liposomes (35). However, the delivery of this drug faces biological challenges, as liposomes encounter several defence systems intended at recognition, neutralization and elimination of invading substances (36).

\section{Stem cells}

Stem cells are special human cells that are capable to mature into various different cell types (37). Stem cells are also characterized as undifferentiated cells that have significant prospective to mature into different cell types in human body throughout early growth and life (38). These cells have the ability to differentiate into any cell types and self-regeneration. Stem cells have two significant features that differentiate them from other cell types. These unspecialized cells able to renew themselves by cell division. These cells can be triggered to proliferate as tissue or organ specific cells with distinct purposes, under certain experimental or physiologic parameters (38).

\section{Sources and types of stem cells}

Stem cells originate mainly from adult body tissues and embryos. The accessible autologous stem cells sources are from the bone marrow, brain, skeletal muscles, blood and blood vessels, umbilical cord, skin, and liver (39). There are numerous types of stem cells that can be used for different purposes (40).

\section{Adult stem cells (ASCs)}

ASCs are undifferentiated cells originate from specific differentiated tissues in our body. These cells can differentiate themselves and produce new cells (40). ASCs are used to repair and replace the damaged or dead tissues in the same area, where the stem cells are found in our body (41). Researchers have classified the ASCs into hematopoietic stem cells, mesenchymal stem cells (MSCs), neural stem cells, epithelial stem cells, and skin stem cells. Hematopoietic stem cells are immature cells that grows into numerous types of blood cells. This stem cells are also known as blood stem cells. This stem cells originate from 


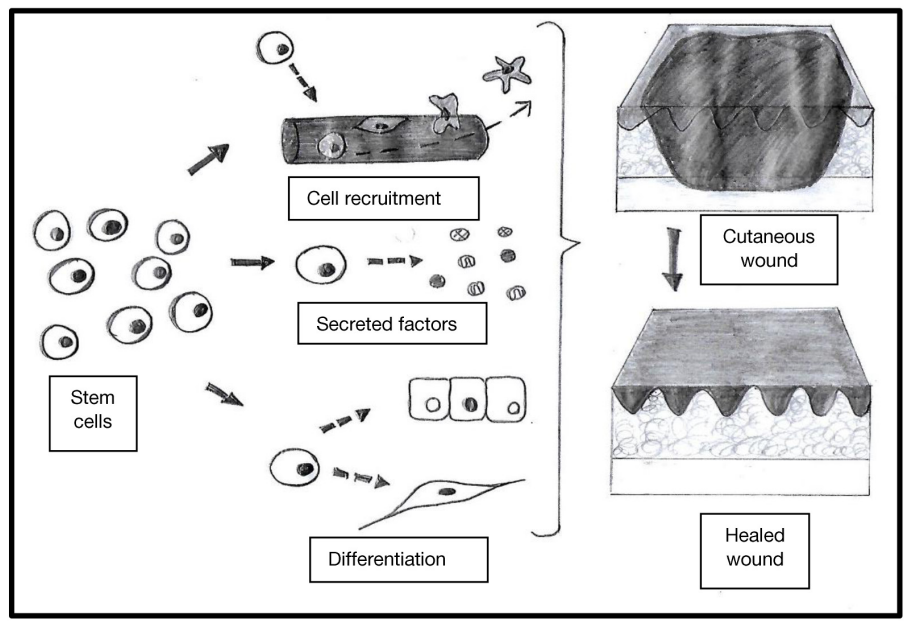

Figure 2 The use of stem cells in wound healing process.

bone marrow and peripheral blood (42).

MSCs are progenitor cells of mesodermal source. In 1970s, MSCs were isolated from bone marrow by their intrinsic capacity to adhere to tissue culture surfaces like plastic (43). Neural stem cells are mostly undifferentiated cells originate from central nervous system. NSCs have the possibility to give rise to offspring cells that develop and differentiate into glial cells and neurons (44). Epithelial stem cells have the potential to generate new tissues that exhibit specific and distinctive purposes (45). Skin stem cells are multipotent ASCs found in adult skin. It occurs in the basal layer of the epidermis and the base of hair follicles. This type stem cells are capable of self-renewal and differentiate into various cell heredities of the skin. Skin stem cells are lively throughout skin regeneration and skin repair after wound (46).

\section{Embryonic stem cells (ESCs)}

ESCs originate from the inner cell mass of an embryo that has been fertilized in vitro. ESCs does not develop from fertilized eggs from human body. These stem cells have the possibility to develop into any cell type and are only available during the primary phases of development. ESCs can be used to regenerate and regrow cells such as skin, nerve and liver for transplantation (40).

\section{Induced pluripotent stem cells (iPSCs)}

iPSCs are produced in the laboratory condition, by means of embryonic and ASCs. iPSCs are generated by introducing the embryonic genes into a somatic cell that causes it to degenerate back into a "stem cell like" condition (40).

\section{Uses of stem cells}

Stem cells can regenerate damaged tissues and function as any type of cell, under precise stimulations and parameters (39). Scientists believe that stem cells can be useful for understanding and treating illnesses due to their capability to develop into different types of cells (41). This possibility could repair wounds or tissue damage and save lives in people after an injury or disease. The role of stem cells in wound management is illustrated in Figure 2 (47). The uses of stem cells include wound care management, tissue regeneration, cardiovascular and brain disease treatment, test new drugs and more (48).

\section{Pros and cons of using stem cells}

Understanding the advantages and disadvantages of various types of stem cells are important in order to avoid the issues of histocompatibility with donor or recipient during transplantation. It is also essential for scientists in drug development and developmental studies. Table 1 outlines some of the pros and cons of stem cells usage in medical industry (49).

\section{Stem cells in wound bealing}

The medications available for wound healing require longer duration for recovery. The delay in wound 
Table 1 Pros and cons of using stem cells (49)

\begin{tabular}{ll}
\hline Pros & Cons \\
\hline $\begin{array}{l}\text { Stem cells are significant in medical industry for cloning and } \\
\text { regenerative medicine }\end{array}$ \\
$\begin{array}{l}\text { Stem cells are capable for discovering novel cures for various Embryonic stem cells may not be the cure for all the diseases } \\
\text { ailments }\end{array}$ \\
$\begin{array}{l}\text { Stem cells aid the researchers to study about human growth and } \\
\text { development }\end{array} \begin{array}{l}\text { Stem cells have potenty of the adult stem cells are pre-specialized } \\
\text { used them in transplantation }\end{array}$ \\
\hline
\end{tabular}

healing procedure leads to development of pus and other complications. Besides, comorbidity such as diabetes delays the normal wound healing process and raise the development of chronic wound (50). Moreover, the intake of certain drugs give rise to side effects such as constipation, liver damage, kidney problems and more. Therefore, several new treatments for wound healing are presently being evaluated in preclinical and clinical studies. Among these new therapies, stem cell-based modality has gained attention to improve tissue regeneration in wound care management (51).

The basis of stem cell-based therapy is the vaccination of cells acquired by various methods. The adult primary cells are developed in in vitro parameters and then implanted directly to the patient. The biopsied tissues comprise of ASCs that are capable to multiply and differentiate into a specific type cells that are essential in healing of wounds (52). Stem cell's wound healing prospective is mainly due to their capability to secrete pro-regenerative cytokines (53). In patients with critical limb ischemia, treatment with autologous MSCs could lessen the practice of amputation (54). Therefore, stem cell-based therapy can be considered as an effective treatment for diabetic foot ulcer, since it can be used as a substitute for amputation.

\section{Molecular mechanisms of stem cells in wound bealing}

MSCs has the tendency to attach on a malleable surface due to their expression of the surface markers CD73, CD90 and CD105 and deficiency of hematopoietic markers expression (55). MSCs that are incorporated both locally and systemically for treating cutaneous wounds are generally isolated from umbilical cord, bone marrow, nerve tissue and adipose tissue (56).

MSCs has significant roles in the three overlapping phases of wound healing: inflammatory phase, proliferative phase and remodelling phase. MSCs exhibit their immunomodulatory properties through secretion of proinflammatory cytokines tumor necrosis factor- $\alpha$ (TNF- $\alpha$ ) , interferon- $\lambda$, interleukin- $1 \alpha$ (IL- $1 \alpha$ ) and IL-1 $\beta$ (57). The administration of MSCs to an active immune response declines the secretion of IFN- $\lambda$ and TNF- $\alpha$ and increases the fabrication of anti-inflammatory cytokines IL-10 and IL-4 (58).

MSCs exhibit its significance by promoting the formation of new vessel and extracellular matrix, mediates cell proliferation and cell differentiation during wound management through the secretion of VEGF, keratinocyte growth factor, matrix metalloproteinase-9, insulin-like growth factor, and epidermal growth factor $(59,60)$. MSCs normalize inflammation and promote wound healing through secretion of PGE-2 (61). Lastly, MSCs also possess bactericidal properties by secretion of antimicrobial factors and by increasing the process of phagocytosis in wound healing (62).

\section{Conclusions}

Stem cells hold a great prospective in tissue regeneration and promoting wound repair. MSCs therapy in wound care management showed a great potential as a therapeutic modality in clinical approach. The use of MSCs in tissue regeneration and wound healing hold a great challenge for modern regenerative medications. However, further studies are essential to distinguish and categorize the best source of stem cells and the most effective approach of cell delivery in wound care.

\section{Acknowledgments}

We express our sincere gratefulness to Professor Dr. Vilasini Pillai, the Dean of Faculty of Science and Technology for 
continuous support and encouragement to develop our research and academic expertise.

Funding: None.

\section{Footnote}

Conflicts of Interest: All authors have completed the ICMJE uniform disclosure form (available at http://dx.doi. org/10.21037/sci-2020-027). The authors have no conflicts of interest to declare.

Ethical Statement: The authors are accountable for all aspects of the work in ensuring that questions related to the accuracy or integrity of any part of the work are appropriately investigated and resolved.

Open Access Statement: This is an Open Access article distributed in accordance with the Creative Commons Attribution-NonCommercial-NoDerivs 4.0 International License (CC BY-NC-ND 4.0), which permits the noncommercial replication and distribution of the article with the strict proviso that no changes or edits are made and the original work is properly cited (including links to both the formal publication through the relevant DOI and the license). See: https://creativecommons.org/licenses/by-nc-nd/4.0/.

\section{References}

1. Kim DJ, Mustoe T, Clark RA. Cutaneous wound healing in aging small mammals: a systematic review. Wound Repair Regen 2015;23:318-9.

2. Agarwal PK, Singh A, Gaurav K, et al. Evaluation of wound healing activity of extracts of plantain banana (Musa sapientum var. Paradisiacal) in rats. Indian J Exp Biol 2009;47:32-40.

3. Murthy S, Gautam MK, Goel S, et al. Evaluation of in vivo wound healing activity of Bacopa monniera on different wound models in rats. Biomed Res Int 2013;2013:972028.

4. Diegelmann RF, Evans MC. Wound healing: an overview of acute, fibrotic and delayed healing. Front Biosci 2004;9:283-9.

5. Sinno H, Prakash S. Complements and the wound healing cascade: an updated review. Plast Surg Int 2013;2013:146764.

6. Barua CC, Talukdar A, Barua AG, et al. Evaluation of the wound healing activity of methanolic extract of Azadirachta indica (Neem) and Tinospora cordifolia (Guduchi) in rats. Pharmacologyonline 2010;1:70-7.
7. Young A, McNaught C. The physiology of wound healing. Surgery (Oxford) 2011;29:475-9.

8. Tonnesen MG, Feng X, Clark RA. Angiogenesis in wound healing. J Investig Dermatol Symp Proc 2000;5:40-6.

9. Clark RAF. Fibrin and wound healing. Ann NY Acad Sci 2001;936:355-67.

10. Osei-Djarbeng SN, Cutler SJ, Cutler RR, et al. Fibroblast growth stimulation, DPPH antioxidant assay and antimicrobial activities of Funtumia elastic (Preuss) Stapf (Apocynaceae) leaf extract. European J Med Plants 2014;4:835-43.

11. Brett D. A review of collagen and collagen-based wound dressings. Wounds 2008;20:347-56.

12. Maxson S, Lopez EA, Yoo D, et al. Concise review: role of mesenchymal stem cells in wound repair. Stem Cells Transl Med 2012;1:142-9.

13. Velnar T, Bailey T, Smrkolj V. The wound healing process: an overview of the cellular and molecular mechanisms. J Int Med Res 2009;37:1528-42.

14. Olczyk P, Mencner L, Komosinsla-Vassev K. The role of the extracellular matrix components in cutaneous wound healing. Biomed Res Int 2014;2014:747584.

15. Barchitta M, Maugeri A, Favara G, et al. Nutrition and wound healing: an overview focusing on the beneficial effects of curcumin. Int J Mol Sci 2019;20:1119.

16. Dorai AA. Wound care with traditional, complementary and alternative medicine. Indian J Plast Surg 2012;45:418-24.

17. Traditional medicine. World Health Organization 2008. Available online: https://www.afro.who.int/health-topics/ traditional-medicine

18. Aggarwal BB, Kumar A, Bharti AC. Anticancer potential of curcumin: preclinical and clinical studies. Anticancer Res 2003;23:363-98.

19. Lestari ML, Indrayanto G. Curcumin. Profiles Drug Subst Excip Relat Methodol 2014;39:113-204.

20. Reddy RC, Vatsala PG, Keshamouni VG, et al. Curcumin for malaria therapy. Biochem Biophys Res Commun 2005;326:472-4.

21. Vera-Ramirez L, Perez-Lopez P, Varela-Lopez A, et al. Curcumin and liver disease. Biofactors 2013;39:88-100.

22. Bielefeld KA, Amini-Nik S, Alman BA. Cutaneous wound healing: recruiting developmental pathways for regeneration. Cell Mol Life Sci 2013;70:2059-81.

23. Song Z, Revelo X, Shao W, et al. Dietary curcumin intervention targets mouse white adipose tissue inflammation and brown adipose tissue UCP1 expression. Obesity 2018;26:547-58.

24. Tapia E, Sánchez-Lozada LG, García-Niño WR, et al. 
Curcumin prevents maleate-induced nephrotoxicity: relation to hemodynamic alterations, oxidative stress, mitochondrial oxygen consumption and activity of respiratory complex I. Free Radic Res 2014;48:1342-54.

25. Gopinath D, Ahmed MR, Gomathi K, et al. Dermal wound healing processes with curcumin incorporated collagen films. Biomaterials 2004;25:1911-7.

26. Mohanty C, Das M, Sahoo SK. Sustained wound healing activity of curcumin loaded oleic acid based polymeric bandage in a rat model. Mol Pharm 2012;9:2801-11.

27. Boudreau MD, Beland FA. An evaluation of the biological and toxicological properties of Aloe barbadensis (Miller), Aloe vera. J Environ Sci Health C Environ Carcinog Ecotoxicol Rev 2006;24:103-54.

28. Pereira RF, Bartolo PJ. Traditional therapies for skin wound healing. Adv Wound Care (New Rochelle) 2016;5:208-29.

29. Oliveira de Sousa AT, Soares MJGO, Oliveira SHS, et al. Biotechnology in the vascular ulcer treatment: case study. 2013;31:101-7.

30. Azevedo JSJ, Juliao ELD, Dantas JBL, et al. Is aloe vera effective for wound healing? The state of the art. J Oral Diag 2019;4:e20190005.

31. Alternative medicine. World Health Organization 2010. Available online: https://www.who.int/healthtopics/traditional-complementary-and-integrativemedicine\#tab=tab_1

32. The 4 medications that inhibit wound healing. Advanced Tissue 2015. Available online: https://www.advancedtissue. com/the-4-medications-that-inhibit-wound-healing/

33. Guo S, DiPietro LA. Factors affecting wound healing. J Dent Res 2010;89:219-29.

34. Krischak GD, Augat P, Claes L, et al. The effects of nonsteroidal anti-inflammatory drug application on incisional wound healing in rats. J Wound Care 2007;16:76-8.

35. Roesken F, Uhl E, Menger MD, et al. Acceleration of wound healing by topical drug delivery via liposomes. Langenbecks Arch Surg 2000;385:42-9.

36. Sercombe L, Veerati T, Moheimani F, et al. Advances and challenges of liposome assisted drug delivery. Front Pharmacol 2015;6:286.

37. Freeborn D, Cunningham L. What are stem cells? Health Encyclopaedia 2019. Available online: https://www.urmc. rochester.edu/encyclopedia/content.aspx? contenttypeid=1 $60 \&$ contentid $=38$

38. Bethesda MD. Stem cell basics. National Institutes of Health 2016. Available online: https://stemcells.nih.gov/ info/basics/1.htm
39. Brazier Y. What are stem cells, and what do they do? 2018. Available online: https://www.medicalnewstoday.com/ articles/323343.php

40. Types of stem cells. National Institutes of Health 2018. Available online: https://www.unmc.edu/stemcells/ educational-resources/ types.html

41. Cafasso J. Stem cell research. Healthline 2016. Available online: https://www.healthline.com/health/stem-cellresearch

42. Hordyjewska A, Popiolek L, Horecka A. Characteristics of hematopoietic stem cells of umbilical cord blood. Cytotechnology 2015;67:387-96.

43. Hassouna A, Elgwad MMA, Fahmy H. Stromal stem cells: nature, biology and potential therapeutic applications. Intech Open 2018. Available online: https://www. intechopen.com/books/stromal-cells-structure-functionand-therapeutic-implications/stromal-stem-cells-naturebiology-and-potential-therapeutic-applications

44. Tang C, Wang M, Wang P, et al. Neural stem cells behave as a functional niche for the maturation of new born neurons through the secretion of PTN. Neuron 2019;101:32-44.e6.

45. Blanpain C, Horsley V, Fuchs, E. Epithelial stem cells: turning over new leaves. Cell 2007;128:445-58.

46. Zakrzewski W, Dobrzynski M, Szymonowicz M, et al. Stem cells: past, present, and future. Stem Cell Res Ther 2019;10:68.

47. McArdle A, Paik KJ, Chung MT, et al. Manipulation of stem cells and their microenvironment for tissue engineering. Surgery Curr Res 2013;3:134.

48. Kirby GT, Mills SJ, Cowin AJ, et al. Stem Cells for Cutaneous Wound Healing. Biomed Res Int 2015;2015:285869.

49. Dearden E. Stem cell research advantages and disadvantages. 2013. Available online: https://getrevising. co.uk/grids/stem_cell_research_advantages_and_ disadvantages

50. Rando TA. Stem cells, ageing and the quest for immortality. Nature 2006;441:1080-6.

51. Duscher D, Barrera J, Wong VW, et al. Stem cells in wound healing: the future of regenerative medicine? A mini-review. Gerontology 2016;62:216-25.

52. Sampogna G, Guraya SY, Forgione A. Regenerative medicine: historical roots and potential strategies in modern medicine. J Microsc Ultrastruct 2015;3:101-7.

53. Garg RK, Rennert RC, Duscher D, et al. Capillary force seeding of hydrogels for adipose-derived stem cell delivery in wounds. Stem Cells Transl Med 2014;3:1079-89. 
54. Procházka V. Cell therapy, a new standard in management of chronic critical limb ischemia and foot ulcer. Cell Transplant 2010;19:1413-24.

55. Dominici M, Le Blanc K, Mueller I, et al. Minimal criteria for defining multipotent mesenchymal stromal cells. The International Society for Cellular Therapy position statement. Cytotherapy 2006;8:315-7.

56. Caplan AI, Dennis JE. Mesenchymal stem as trophic mediators. J Cell Biochem 2006;98:1076-84.

57. Ren G, Zhang L, Zhao X, et al. Mesenchymal stem cell-mediated immunosuppression occurs via concerted action of chemokines and nitric oxide. Cell Stem Cell 2008;2:141-50.

58. Aggarwal S, Pittenger MF. Human mesenchymal stem cells modulate allogeneic immune cell responses. Blood

doi: $10.21037 /$ sci-2020-027

Cite this article as: Ayavoo T, Murugesan K, Gnanasekaran A. Roles and mechanisms of stem cell in wound healing. Stem Cell Investig 2021;8:4.
2005;105:1815-22.

59. Rustad KC, Wong VW, Sorkin M, et al. Enhancement of mesenchymal stem cell angiogenic capacity and stemness by a biomimetic hydrogel scaffold. Biomaterials 2012;33:80-90.

60. Badiavas EV, Falanga V. Treatment of chronic wounds with bone marrow-derived cells. Arch Dermatol 2003;139:510-6.

61. Hu MS, Rennert RC, McArdle A, et al. The role of stem cells during scarless skin wound healing. Adv Wound Care (New Rochelle) 2014;3:304-14.

62. Mei SH, Haitsma JJ, Dos Santos CC, et al. Mesenchymal stem cells reduce inflammation while enhancing bacterial clearance and improving survival in sepsis. Am J Respir Crit Care Med 2010;182:1047-57. 